\title{
Smoking burden, MPOWER, future tobacco control and real-world challenges in China: reflections on the WHO report on the global tobacco epidemic 2021
}

\author{
Kaiping Zhang1, Alfredo Tartarone ${ }^{2}$, Mónica Pérez-Ríos ${ }^{3}$, Silvia Novello ${ }^{4}$, Annapaola Mariniello ${ }^{4}$, \\ Giandomenico Roviello ${ }^{5}$, Jianrong Zhang ${ }^{6}$
}

${ }^{1}$ Editorial Office, AME Publishing Company, Hong Kong, China; ${ }^{2}$ Division of Medical Oncology, Department of Onco-Hematology, IRCCSCROB, Referral Cancer Center of Basilicata, Rionero in Vulture (PZ), Italy; ${ }^{3}$ Preventive Medicine and Public Health Department, University of Santiago de Compostela; CIBER de Epidemiología y Salud Pública (CIBERESP); Health Research Institute of Santiago de Compostela (IDIS), Santiago de Compostela, Spain; ${ }^{4}$ Department of Oncology, University of Turin, AOU San Luigi Gonzaga, Orbassano, Torino, Italy; ${ }^{5}$ Department of Health Sciences, University of Florence, Florence, Italy; ${ }^{6}$ Centre for Cancer Research \& Department of General Practice, Faculty of Medicine, Dentistry and Health Sciences, University of Melbourne; Victorian Comprehensive Cancer Centre, Melbourne, Victoria, Australia

Correspondence to: Jianrong Zhang, MD, MPH. Centre for Cancer Research \& Department of General Practice, Faculty of Medicine, Dentistry and Health Sciences, University of Melbourne; Victorian Comprehensive Cancer Centre, Level 10/305 Grattan St, Melbourne VIC 3000, Australia. Email: jianrong.zhang@unimelb.edu.au.

Submitted Jan 10, 2022. Accepted for publication Jan 21, 2022.

doi: $10.21037 /$ tlcr-22-27

View this article at: https://dx.doi.org/10.21037/tlcr-22-27

On July 27, 2021, the World Health Organization (WHO) released its latest (the eighth) report on the global tobacco epidemic (1). The report tracks the progress made by countries in tobacco control since 2008, including China. Of note, the report highlights the global progress especially implementations according to the six MPOWER policies ["monitor tobacco use and prevention policies $(M)$; protect people from tobacco smoke (P); offer help to quit tobacco use $(\mathrm{O})$; warn about the dangers of tobacco $(\mathrm{W})$; enforce bans on tobacco advertising, promotion \& sponsorship (E); and raise taxes on tobacco (R)"], but raises new challenges including electronic nicotine delivery systems (1). Given China's critical role in global tobacco control, we write this article to highlight where China is now in tobacco control, including the smoking burden as well as the current progress, future direction and real-world challenges based on the MPOWER policies.

\section{Smoking burden globally}

Tobacco (smoked, secondhand, and chewing) was associated with 8.71 million deaths globally in 2019 (1). Despite the decline in tobacco smoking exposure from 2010 to 2019 (over $1 \%$ per year, age-standardised), tobacco remains the third leading risk factor for attributable disability-adjusted life-years (DALYs) among Level 2 risks defined by the Global Burden of Disease Study (2). Specifically, tobacco smoking led to 7.69 million deaths and 200 million DALYs, accounting for 13.6\% of all human deaths and $7.89 \%$ of all DALYs (3). Following population growth, the number of smokers increased from 0.99 million in 1990 to 1.14 billion in 2019. However, within this period, aged-standardised prevalence of smoking tobacco among males aged 15 years and older decreased by $27.5 \%$ (95\% CI: 26.5-28.5\%) and among females decreased by $37.7 \%$ (95\% CI: 35.4-39.9\%) (3).

The dramatic decrease in smoking prevalence results from substantial global and local tobacco control efforts (4). In particular, the adoption of the Framework Convention on Tobacco Control (FCTC) by the WHO in 2003 (5) and the recognition of tobacco burden in the United Nations Sustainable Development Goals have been pivotal (4). To help countries better manage the implementation of effective interventions on tobacco control, WHO introduced the MPOWER measures (1). 


\section{Smoking burden in China}

Despite encouraging results globally, some regions and countries have seen less improvement in reducing smoking prevalence, including China. Between 1990 and 2019, smoking prevalence in China decreased less than the global average (2). In 2019, China had 341 million smokers (24\% of China's population of 1.4 billion) who consumed onethird of the world's consumption, with smoking prevalence as high as $49.7 \%$ in males and $3.54 \%$ in females (2). China is facing significant tobacco-attributable disease burden, including cardiovascular disease especially ischemic heart disease, lung cancer, chronic obstructive pulmonary disease and stroke $(6,7)$, as well as related economic costs (57-368 billion RMB per year) (8). More importantly, China has the largest absolute increase in the number of deaths attributed to tobacco smoking in the period of 1990-2019, with a total of 2.4 million deaths in 2019 , accounting for $31.2 \%$ of the 7.69 million deaths globally (3). As such, tobacco control in China has been and will continue to be an essential part of the global efforts.

\section{China's MPOWER in the WHO report on the global tobacco epidemic 2021}

In 2003, China signed the WHO FCTC, which was ratified in 2005 and came into legal force in 2006. To fully implement the WHO FCTC, China has also adopted the MPOWER measures and shown continuous progress in WHO reports.

Achievements in WHO's MPOWER measures are assessed as (from the highest to the lowest): complete, moderate, minimal, and no or weak policies $(1,9)$. In the WHO report on the global tobacco epidemic 2019, none of the six MPOWER policies in China was complete (9). However, the situation improved in the 2021 WHO report (1), with China receiving the following ratings: $(\mathrm{M})$ monitoring tobacco use and impact of prevention policies-complete; $(\mathrm{P})$ protect people for tobacco use-no or weak; $(\mathrm{O})$ offer help to quit tobacco use-moderate; (W) health warning policiesminimal, and mass media policies—complete; (E) advertising, promotion or sponsorship-moderate; and $(\mathrm{R})$ raise taxes on tobacco $(54.5 \%)$-moderate (1).

Overall, the current progress in the MPOWER measures contributed to the prevalence drop in daily smoking from $30.5 \%$ in the 2008 report (10) to $23 \%$ in the 2021 report (1). Encouragingly, monitoring and mass media have reached the highest level. To achieve the effectiveness of current and future tobacco control, China has highlighted the importance of monitoring, with nationally representative and periodically collected data for over 1.4 billion people (1).

\section{Tobacco control: future directions in China}

To guide future improvements, MPOWER will continue to be an important tool. It was estimated that smokingattributable deaths were 14.6 million less in 43 countries adopting at least one MPOWER policy at the highest level between 2014 and 2016 (11). As indicated in the updated report (1), future improvement is needed in protecting people from tobacco smoke $(\mathrm{P})$, warning about the danger of tobacco $(\mathrm{W})$, and raising taxes on tobacco $(\mathrm{R})$.

In the 2021 report, the implementation achievement level for protecting people from tobacco smoke $(\mathrm{P})$ via smoking bans for a smoke-free environment is still the lowest (1). In 2017, secondhand smoke was the 13th leading risk factor for deaths in China and the 12th for DALYs (7). The current secondhand smoking prevalence remains high. With regard to indoor public places and public transportation, the proportion of people smoking was $50.9 \%$ in indoor workplaces, $12.9 \%$ in public transportation, $44.9 \%$ in households, $24.4 \%$ in healthcare facilities, $73.3 \%$ in restaurants, $87.5 \%$ in bars and nightclubs, $23.4 \%$ in elementary/middle schools, and $33.3 \%$ in universities (12). Furthermore, the Global Youth Tobacco Survey (GYTS) has indicated the need of protection for youth: over half of Chinese students (aged 12-16 years) surveyed reported being exposed to second-hand smoke (on 1 or more days during the past 7 days) in any places $(61.1 \%$ in 2001 to $69.7 \%$ in 2015$)$ and at schools $(57.4 \%$ in 2001 to $65.6 \%$ in 2015) (13). Nevertheless, no-smoking policies have been partially in place in Beijing since 2008 and currently exist in over 20 cities, with nearly $10 \%$ of the Chinese population now protected by smoking bans $(6,14)$. In 2014, Beijing passed its strictest smoking control law, banning smoking in all indoor public and workplaces (14). However, most cities still lag behind Beijing. Current evidence has shown that national-level smoke-free legislation has a positive effect on reducing secondhand smoke exposure, tobacco use, inequality, and improving health outcomes $(4,15,16)$. Substantial efforts for a smoke-free environment are expected in China, such as a stronger, more comprehensive nationwide no-smoking law. Also, China should particularly strengthen the protection of youth from tobacco.

Health warnings can have a powerful health impact, including reducing smoking-attributable deaths (11). 
With respect to warning about the danger of tobacco (W), although policies on mass media are complete, policies on health warnings are minimal in China (1). In particular, warnings rely on words, not visuals. For example, tobacco packaging is usually designed with beautiful colors, graceful mountains and rivers, and elegant brand names, rather than visuals depicting health warnings, such as images of lungs damaged by smoking. This could possibly explain the lack of improvement in smoking cessation rates $36.4 \%$ in 2010 ; $19.8 \%$ in 2018) (17). In addition, a Cochrane systematic review showed that plain and standardised packaging could limit the appeal of smoking and reduce the number of people who use tobacco (18). Therefore, more efforts should be made to use visual health warnings and plain and standardised packaging.

Although the level of taxation on tobacco $(R)$ is moderate, cigarettes in China are becoming more affordable (1). As presented in the 2021 report, China's taxation rate is $54.5 \%$ (1), which is a bit lower than the $55.7 \%$ rate reported in 2019 (9). Importantly, cigarettes have become more affordable, as the per capita gross domestic product needed to buy cigarettes has decreased more than $1.45 \%$ since 2010 . A 20 -cigarette pack is cheap, costing from $3 \mathrm{RMB}$ to $50 \mathrm{RMB}$ (about $\$ 0.47$ to $\$ 7.84$ or $€ 0.42$ to €6.96) (1). Research has also shown that cigarette affordability has been increasing, particularly among younger and lower socioeconomic-status smokers (19).

There is substantial evidence confirming that raising taxes on tobacco is one of the potent and cost-effective strategies to increase smoking cessation and specially to reduce the initiation of new smoking $(1,20)$. Research suggests that a $10 \%$ decrease in cigarette affordability could lead to a $1.65 \%$ reduction in cigarette consumption, avert numerous premature deaths, achieve tax revenues, and prevent poverty in China (21). Despite the small decrease in taxation rate from 2019 (9) to 2021 (1), in the past China's tobacco taxation was risen with desirable effects. In particular, after the cigarette tax increased to $36.3 \%$ in 2015, the retail price of cigarettes increased by $11 \%$ on average and annual cigarette sales decreased by $7.8 \%$ from 127 billion to 117 billion packs between 2014 and 2016 (22), with one-fifth of male smokers reporting less smoking in 2016 (23). Meanwhile, tax revenues from cigarettes increased by $14 \%$ from 740 billion to 842 billion RMB between 2014 and 2016, potentially beneficial for public health through the financial benefits raised through taxation (22). Further, one study estimated that China could achieve
7.1 trillion $\mathrm{RMB}$ in total economic savings from the cost of tobacco-attributable noncommunicable diseases for 2015-2030, if China raised the tax on cigarettes to $75 \%$ (24), the benchmark for the highest level recommended by WHO. Based on the above evidence, a further increase in cigarette tax should be considered.

\section{Real-world challenges}

Along with efforts and positive outcomes after reinforcing MPOWER policies, the WHO FCTC raises the point that we also need to recognize "the spread of the tobacco epidemic is facilitated by a variety of complex factors with cross-border effects, including trade liberalization, foreign direct investment, and other activities such as global marketing, transnational tobacco advertising, promotion and sponsorship, and the international movement of contraband and counterfeit cigarettes" (5). Inevitably, we have to face many real-world challenges from policy to implementation.

For tobacco control in China, the following challenges warrant highlighting. First, China National Tobacco Corporation (CNTC) is a government-owned tobacco company responsible for major aspects of China's tobacco industry including growing, manufacturing and distributing. Importantly, CNTC has not only economic attributes, but also administrative attributes and is involved in the WHO FCTC enforcing. This conflict of interest makes the implementation of the above suggested policies face a major obstacle. China may need to establish an independent body with less conflict of interest to implement the WHO FCTC. Since China is the largest producer of tobacco, the strategies to discourage smoking should be accompanied by the promotion of economically viable alternatives for the 1.5 million tobacco growers and over 20 million workers employed in the tobacco industry (25). Furthermore, electronic cigarettes (e-cigarettes) or the electronic nicotine delivery system (ENDS), emerging in recent years, have also challenged tobacco control. In China, e-cigarettes use is increasing while has not received enough attention regarding its hazards and potential interventions on restriction and cessation (26). A survey from five Chinese cities showed that men, young adults with higher levels of education, and current smokers were more likely to be aware of and use ENDS (27). Proper regulations and implementations are needed on the use of e-cigarettes. Last, we should be aware of social norms around smoking, as smoking may still be a 'culture' in many regions. 


\section{Summary}

In conclusion, the burden from tobacco in China and globally is huge. Encouragingly, the 2021 WHO report on the global tobacco epidemic shows that progress has been made in previous years, including in MPOWER measures. However, the implementation of tobacco control is never easy. China's role in achieving a tobacco-free world is essential due to its heavy tobacco-attributable morbidity and mortality burden. The fight against tobacco requires the collaboration of all relevant stakeholders, including a dedicated government, public awareness and support, and collective endeavors among countries.

\section{Acknowledgments}

The authors appreciate the academic support from the AME Public Health Collaborative Group.

Funding: None.

\section{Footnote}

Provenance and Peer Review: This article was a standard submission to the journal. The article has undergone external peer review.

Conflicts of Interest: All authors have completed the ICMJE uniform disclosure form (available at https://tlcr. amegroups.com/article/view/10.21037/tlcr-22-27/coif). $\mathrm{KZ}$ declares that she is a full-time employee of AME Publishing Company (publisher of Translational Lung Cancer Research). JZ serves as an unpaid editorial board member of Pharmacogenomics Research and Personalized Medicine from July 2021 to June 2023. AM received financial support to attend scientific meeting from Amgen. SN received payment or honoraria for lectures, presentations, speakers' bureaus, manuscript writing or educational events from BMS, Eli Lilly, Takeda, Roche, Pfizer, Astrazeneca, BI, MSD, Abbvie, Pharmamar and Beigene, and has participation on a data safety monitoring board or advisory board from Takeda, Janssen-Cilag, Pfizer and Astrazeneca. The other authors have no conflicts of interest to declare.

Ethical Statement: The authors are accountable for all aspects of the work in ensuring that questions related to the accuracy or integrity of any part of the work are appropriately investigated and resolved.
Open Access Statement: This is an Open Access article distributed in accordance with the Creative Commons Attribution-NonCommercial-NoDerivs 4.0 International License (CC BY-NC-ND 4.0), which permits the noncommercial replication and distribution of the article with the strict proviso that no changes or edits are made and the original work is properly cited (including links to both the formal publication through the relevant DOI and the license). See: https://creativecommons.org/licenses/by-nc-nd/4.0/.

\section{References}

1. World Health Organization. WHO report on the global tobacco epidemic 2021: addressing new and emerging products. 2021. Available online: https://www.who.int/ teams/health-promotion/tobacco-control/global-tobaccoreport-2021 (accessed on 28 September 2021).

2. GBD 2019 Risk Factors Collaborators. Global burden of 87 risk factors in 204 countries and territories, 1990-2019: a systematic analysis for the Global Burden of Disease Study 2019. Lancet 2020;396:1223-49.

3. GBD 2019 Tobacco Collaborators. Spatial, temporal, and demographic patterns in prevalence of smoking tobacco use and attributable disease burden in 204 countries and territories, 1990-2019: a systematic analysis from the Global Burden of Disease Study 2019. Lancet 2021;397:2337-60.

4. Flor LS, Reitsma MB, Gupta V, et al. The effects of tobacco control policies on global smoking prevalence. Nat Med 2021;27:239-43.

5. World Health Organization. WHO framework convention on tobacco control. 2003. Available online: https://apps. who.int/iris/bitstream/handle/10665/42811/9241591013. pdf (accessed on 28 September 2021).

6. Wen H, Xie C, Wang F, et al. Trends in Disease Burden Attributable to Tobacco in China, 1990-2017: Findings From the Global Burden of Disease Study 2017. Front Public Health 2020;8:237.

7. Zhou M, Wang H, Zeng X, et al. Mortality, morbidity, and risk factors in China and its provinces, 1990-2017: a systematic analysis for the Global Burden of Disease Study 2017. Lancet 2019;394:1145-58. Erratum in: Lancet 2020;396:26.

8. Shi L, Zhong L, Cai Y. Economic burden of smokingattributable diseases in China: A systematic review. Tob Induc Dis 2020;18:42.

9. World Health Organization. WHO report on the global 
tobacco epidemic 2019: offer help to quit tobacco use. 2019. Available online: https:/www.who.int/publications/ i/item/9789241516204 (accessed on 30 September 2021).

10. World Health Organization. WHO report on the global tobacco epidemic 2008: the MPOWER package. 2010. Available online: https://apps.who.int/iris/ handle/10665/43818 (accessed on 27 October 2021).

11. Levy DT, Li Y, Yuan Z. Impact of nations meeting the MPOWER targets between 2014 and 2016: an update. Tob Control 2020;29:231-3.

12. World Health Organization. 2018 GATS Country Report China. 2018. Available online: https://www.who.int/ publications/m/item/2018-gats-country-report-china (accessed on 1 October 2021).

13. Ma C, Heiland EG, Li Z, et al. Global trends in the prevalence of secondhand smoke exposure among adolescents aged 12-16 years from 1999 to 2018: an analysis of repeated cross-sectional surveys. Lancet Glob Health 2021;9:e1667-78.

14. Yang G, Wang Y, Wu Y, et al. The road to effective tobacco control in China. Lancet 2015;385:1019-28.

15. Brown T, Platt S, Amos A. Equity impact of populationlevel interventions and policies to reduce smoking in adults: a systematic review. Drug Alcohol Depend 2014;138:7-16.

16. Hone T, Szklo AS, Filippidis FT, et al. Smoke-free legislation and neonatal and infant mortality in Brazil: longitudinal quasi-experimental study. Tob Control 2020;29:312-9.

17. Centers of Disease Control and Prevention. Global Tobacco Surveillance System Data (GTSSData). https:// nccd.cdc.gov/GTSS/rdPage.aspx? rdReport=OSH_ GTSS.ExploreByLocation\&rdRequestForwarding=Form (accessed on 20 January 2022).

18. McNeill A, Gravely S, Hitchman SC, et al. Tobacco

Cite this article as: Zhang $\mathrm{K}$, Tartarone A, Pérez-Ríos M, Novello S, Mariniello A, Roviello G, Zhang J. Smoking burden, MPOWER, future tobacco control and real-world challenges in China: reflections on the WHO report on the global tobacco epidemic 2021. Transl Lung Cancer Res 2022;11(1):117-121. doi: $10.21037 /$ tlcr-22-27 packaging design for reducing tobacco use. Cochrane Database Syst Rev 2017;4:CD011244.

19. Nargis N, Zheng R, Xu SS, et al. Cigarette Affordability in China, 2006-2015: Findings from International Tobacco Control China Surveys. Int J Environ Res Public Health 2019;16:1205.

20. Kostova D, Husain MJ, Chaloupka FJ. Effect of cigarette prices on smoking initiation and cessation in China: a duration analysis. Tob Control 2016;26:569-74.

21. Hu X, Wang Y, Huang J, et al. Cigarette Affordability and Cigarette Consumption among Adult and Elderly Chinese Smokers: Evidence from A Longitudinal Study. Int J Environ Res Public Health 2019;16:4832.

22. Goodchild M, Zheng R. Early assessment of China's 2015 tobacco tax increase. Bull World Health Organ 2018;96:506-12.

23. Yu L, Cohen JE, Hoe C, et al. Male smoking reduction behaviour in response to China's 2015 cigarette tax increase. Tob Control 2020;29:405-11.

24. Chen S, Kuhn M, Prettner K, et al. Noncommunicable Diseases Attributable To Tobacco Use In China: Macroeconomic Burden And Tobacco Control Policies. Health Aff (Millwood) 2019;38:1832-9.

25. World Health Organization. World Health Organization FCTC Global Progress Report 2018. 2018. Available online: https://www.who.int/fctc/reporting (accessed on 27 October 2021).

26. Sun S, Veltri GA, Wang F. Representations of electronic cigarettes in Chinese media. BMC Public Health 2018;18:727.

27. Huang J, Duan Z, Wang Y, et al. Use of Electronic Nicotine Delivery Systems (ENDS) in China: Evidence from Citywide Representative Surveys from Five Chinese Cities in 2018. Int J Environ Res Public Health 2020;17:2541. 